\section{A more correct interpretation}

A systematic review and meta-analysis of arthroscopic surgery for degenerative tears of the meniscus was recently published on cmaj.ca. ${ }^{1}$ We commend the authors for their timely work summarizing the available scientific evidence.

The authors evaluated "the efficacy of arthroscopic meniscal débridement in comparison with nonoperative or sham treatments." This is correct for the study comparing arthroscopic surgery to sham surgery, ${ }^{2}$ the study comparing arthroscopic surgery to steroid injection ${ }^{3}$ and the study comparing arthroscopic surgery to medical exercise therapy. ${ }^{4}$ However, this aim is incorrectly stated for the studies by Herrlin and colleagues, ${ }^{5}$ Katz and colleagues, ${ }^{6}$ and Yim and colleagues, ${ }^{7}$ where exercise was a component of treatment provided to both groups. These three latter studies together comprise the majority of patients, 522 out of 805 , included in this meta-analysis, and they studied the additional effect of a combination of arthroscopic surgery and exercise in comparison with exercise alone. Thus, a comparison of the effects from arthroscopic surgery alone to exercise alone is not possible.

A more correct interpretation of the results from the meta-analysis would therefore be, "there is moderate evidence to suggest that there is no additional benefit of arthroscopic meniscal débridement for degenerative meniscal tears compared to exercise, and no benefit in comparison with sham surgery or injection therapy."

Ewa M. Roos PT PhD, Jonas B. Thorlund PhD, Carsten B. Juhl PhD, L. Stefan Lohmander MD PhD Department of Sports and Clinical Biomechanics (Roos, Thorlund, Juhl, Lohmander), University of Southern Denmark, Odense; Department of Orthopedics (Juhl), Copenhagen University, Copenhagen; Department of Orhtopedics and Traumatology (Lohmander), Odense University Hospital, Odense, Denmark; Department of Orthopedics (Lohmander) Clinical Sciences Lund, University of Lund, Sweden.

\section{References}

1. Khan M, Evaniew N, Bedi A, et al. Arthroscopic surgery for degenerative tears of the meniscus: a systematic review and meta-analysis. CMAJ 2014;186:1057-64.
2. Sihvonen R, Paavola M, Malmivaara A, et al. Arthroscopic partial meniscectomy versus sham surgery for a degenerative meniscal tear. $N$ Engl J Med 2013;369:2515-24

3. Vermesan D, Prejbeanu R, Laitin S, et al. Arthroscopic debridement compared to intra-articular steroids in treating degenerative medial meniscal tears. Eur Rev Med Pharmacol Sci 2013;17:3192-6.

4. Osteras H, Osteras B, Torstensen TA. Medical exercise therapy, and not arthroscopic surgery, resulted in decreased depression and anxiety in patients with degenerative meniscus injury. $J$ Bodyw Mov Ther 2012;16:456-63.

5. Herrlin S, Hallander $M$, Wange $P$, et al. Arthroscopic or conservative treatment of degenerative medial meniscal tears: a prospective randomised trial. Knee Surg Sports Traumatol Arthrosc 2007; 15:393-401.

6. Katz JN, Brophy RH, Chaisson CE, et al. Surgery versus physical therapy for a meniscal tear and osteoarthritis. N Engl J Med 2013;368:1675-84.

7. Yim JH, Seon JK, Song EK, et al. A comparative study of meniscectomy and nonoperative treatment for degenerative horizontal tears of the medial meniscus. Am J Sports Med 2013;41:1565-70.

CMAJ 2015. DOI:10.1503/cmaj. 1150018

\section{Obesity solutions?}

We read Fletcher and Patrick's article summarizing the failure of "educational programs" to stem the obesity epidemic, concluding that "obesity will only be curbed by population-level measures supported by legislation."1

We would like to draw attention to the Ensemble Prévenons l'Obésité Des Enfants (EPODE) methodology that has evolved over the past 22 years and has been shown to reduce the prevalence of childhood obesity in largescale studies in Europe (overweight and obese children are predictors of obesity in adults)..$^{2,3}$ It is important to note that none of the EPODE communities has chosen to use legislation to regulate or change behaviours. Most EPODE programs are funded by a combination of public and private partnerships.

EPODE's capacity-building for communities integrates both nutrition and physical activity. The EPODE methodology focuses on families and involves the full range of stakeholders including schools, parks, health care practitioners, private partners and politicians at all levels.

Through the mobilization of community, we can shift norms from obesogenic environments to broad adoption of healthy active living practices.

EPODE Canada (epodecanada.ca) is a new regional initiative of the EPODE International Network. EPODE is just getting started in Can- ada, having been chosen as the framework for Ontario's Healthy Kids Community Challenge.

\section{Dennis Edell BA}

Managing Director, EPODE Canada

\section{References}

1. Fletcher J, Patrick K. A political prescription is needed to treat obesity. CMAJ 2014;186:1275.

2. Borys JM, de Ruyter JC, Finch H, et al. Hydration and obesity prevention. Obes Facts 2014;7(Suppl 2):37-48.

3. Romon M, Lommez A, Tafflet M, et al., Downward trends in the prevalence of childhood overweight in the setting of 12-year school- and community-based programmes. Public Health Nutr, 2009;12:1735-42.

Competing interests: The EPODE International Network is supported by grants from both public partners such as the European Union and private partners such as Nestle and Coca Cola.

CMAJ 2015. DOI:10.1503/cmaj. 1150019

Thank you for your excellent editorial ${ }^{1}$ on the tender topic of obesity.

As Canadians, we are pampered with a perceived entitlement to health care no matter how much we have subjected ourselves to health risks.

Dr. Norman Campbell, now at the University of Calgary, has been a longtime advocate for the model used in North Karelia, Finland where the use of "The Fat Tax" (and I apologize for these offensive three-letter words) has resulted in sustained benefits to the local population with a reduction in hypertension, heart disease and stroke over a period of more than 30 years. We would love to see this in Canada. ${ }^{2,3}$

Although Fletcher and Patrick's solution has merit, it may cause Canadians countrywide to choke on the political pill they are suggesting we swallow. Ironically, we would be healthier. What do we really want I wonder? Clearly having our cake, and eating so much of it, is not working.

Jane Alabaster MD

Family physician, Calgary, Alta.

\section{References}

1. Fletcher J, Patrick K. A political prescription is needed to treat obesity. CMAJ 2014;186:1275.

2. Campbell N, Duhaney T, Arango M, et al. Healthy food procurement policy: an important intervention to aid the reduction in chronic non-communicable diseases. Can J Cardiol 2014;30:1456-9.

3. Duhaney T, Campbell N, Niebylski ML, et al. Death by diet: the role of food pricing interventions as a public policy response and health advocacy opportunity. Can J Cardiol 2015;31:112-6.

CMAJ 2015. DOI:10.1503/cmaj. 1150020 